\title{
Analisis Kualitas Alginat Rumput Laut (Padina sp.) Menggunakan Metode Ekstraksi Jalur Kalsium
}

\author{
Adam Sojuangon Pasaribu*, Sri Sedjati, Rini Pramesti \\ Departemen IImu Kelautan, Fakultas Perikanan dan IImu Kelautan, Universitas Diponegoro \\ JI. Prof. H. Soedarto S.H, Tembalang, Semarang, Jawa Tengah 50275 Indonesia \\ *Corresponding author, e-mail : adamsojoangunpasaribu@gmail.com
}

\begin{abstract}
ABSTRAK: Padina sp. merupakan spesies rumput laut cokelat (Phaeophyta) penghasil alginat, namun kualitas alginat yang dihasilkan tergolong rendah dibandingkan alginofit lainnya. Metode ekstraksi jalur kalsium diduga dapat meningkatkan kualitas alginat sehingga penelitian ini perlu dilakukan. Tujuan penelitian ini untuk mengkaji apakah ekstraksi jalur kalsium dapat meningkatkan mutu alginat yang dihasilkan dari rumput laut Padina. Ekstraksi dilakukan dengan metode jalur kalsium konvensional dan jalur kalsium MAE (Microvawe Assisted Extraction). Metode penelitian yang digunakan adalah eksperimental laboratoris dengan 1 perlakuan (kosentrasi $\mathrm{Ca} \mathrm{Cl}_{2}$ ) dan 3 taraf konsentrasi yaitu $0,5 \mathrm{M} 1,0 \mathrm{M}$ dan 1,5 M. Parameter kualitas yang dianalisis meliputi rendemen, kadar air, Kadar abu, viskositas, pH dan FTIR. Hasil uji two way ANOVA menunjukan terdapat signifikansi rendemen dengan nilai 0,007. Metode jalur kalsium MAE dengan konsentrasi 1,0 M Ca Cl 2 menghasilkan kualitas terbaik dengan nilai rendemen (26,83\%), kadar air (10,67\%), kadar abu (21,83\%), viskositas $(11,42 \mathrm{cPs})$ dan $\mathrm{pH}(6,77)$. Hasil analisis FTIR menunjukan ke-2 metode ekstraksi menghasilkan natrium alginat dengan adanya sidik jari guluronat dan manuronat pada bilangan gelombang $930-890 \mathrm{~cm}^{-1}$ dan $870-820 \mathrm{~cm}^{-1}$.
\end{abstract}

Kata kunci : Jalur kalsium; MAE; natrium alginat; FTIR; Padina sp.

\section{Quality Analysis Of Seaweed Alginates (Padina sp.) Using Calcium Path Extraction Method}

ABSTRACT: Padina sp. is a species of brown seaweed (Phaephyta) producing alginates, but the quality of alginates produced is relatively low compared to other alginophytes. The calcium pathway extraction method is thought to improve the quality of alginates thus the reason of the research. This research aims to examine whether the calcium pathway extraction improves the quality of alginates produced from Padina. Seaweed extraction was carried out using conventional calcium pathways and MAE (Microwave Assisted Extraction) calcium pathways. The research method used was laboratory experimental with 1 treatment ( $\mathrm{Ca} \mathrm{Cl} 2$ concentration) and 3 concentration levels : $0.5 \mathrm{M}, 1.0 \mathrm{M}, 1.5 \mathrm{M}$. Quality parameters analyzed includes yield, moisture content, ash contetnt, viscosity, $\mathrm{pH}$ and FTIR. The two way ANOVA test results showed that there was a significance of yield value of 0.007 . The MAE calcium pathway method with a concentration of $1.0 \mathrm{M} \mathrm{Ca} \mathrm{Cl}_{2}$ produces the best quality with a yield value (26.83\%), water content $(10.67 \%)$, ash content (21.83\%), viscosity (11.42 cPs) and $\mathrm{pH}$ (6.77). FTIR analysis results show that the two extraction methods produces sodium alginate in the presence of guluronate and manuronic fingerprints at wave numbers $930-890 \mathrm{~cm}^{-1}$ and $870-820 \mathrm{~cm}^{-1}$.

Keywords : Calcium pathway; MAE; sodium alginate; FTIR; Padina sp.

\section{PENDAHULUAN}

Alginat merupakan hasil laut yang mempunyai nilai ekonomis tinggi karena dibutuhkan dalam berbagai bidang industri (Sinurat dan Marliani, 2017). Rumput laut penghasil alginat (alginofit) di perairan sangat melimpah, namun belum dimanfaatkan secara baik (Septiani et al., 
2017). Alginat merupakan komponen utama dari getah rumput laut cokelat (Phaeophyta) yang terletak pada dinding sel (Abid et al., 2019). Pemanfaatan alginat di Indonesia masih terkendala oleh rendahnya mutu alginat yang dihasilkan. Salah satu cara dalam meningkatkan kualitas alginat adalah dengan melakukan pengembangan metode ekstraksi alginat (Husni et al., 2012; Maharani et al., 2017 dan Diharningrum dan Husni, 2018).

Ekstraksi alginat di Indonesia masih menggunakan metode jalur asam (Mushollaeni dan Rusdiana, 2011, Widiyanti dan Siswanto., 2012; Anwar et al., 2013 dan Mirza et al., 2013). Pengembangan metode ekstraksi alginat menggunakan jalur kalsium dilakukan (Husni et al., 2012), dengan membandingkan metode ekstraksi jalur asam dan jalur kalsium. Ekstraksi dengan jalur asam dapat menghasilkan viskositas yang tinggi namun rendemennya rendah. Metode jalur kalsium mempunyai keunggulan yaitu rendemen yang dihasilkan tinggi namun viskositasnya rendah. Metode jalur kalsium mengalami modifikasi ekstraksi, yaitu MAE (Microwave assisted extraction). Ekstraksi jalur kalsium dengan MAE dapat menghasilkan rendemen dan viskositas yang lebih baik dibandingkan dengan ekstraksi jalur kalsium konvensional (Silva et al., 2015).

Spesies alginofit salah satunya adalah Padina sp. (Asih et al., 2019). Alginat yang dihasilkan oleh rumput laut ini memiliki rendemen yang tergolong rendah yaitu 17,82\% (Septiani et al., 2017). Rendemen dapat ditingkatkan dengan ekstraksi jalur kalsium alginat (Diharningrum dan Husni, 2018). Penelitian ini bertujuan untuk mengembangkan metode ekstraksi alginat dari rumput laut Padina sp. dengan metode kalsium MAE sehingga dapat meningkatkan kualitas alginat yang dihasilkan.

\section{MATERI DAN METODE}

Materi yang digunakan adalah rumput laut Padina sp. yang diperoleh dari Pantai Pok Tunggal, Gunung Kidul, Provinsi D.I Yogyakarta. Pengukuran suhu, DO(dissolved oxygen), salinitas, dan $\mathrm{pH}$ dilakukan bersamaan dengan pengambilan sampel. Sampel dikeringkan dibawah sinar matahari hingga kadar air $<10 \%$, kemudian disimpan.

Ekstraksi jalur kalsium (Husni et al., 2012), sampel sebanyak $50 \mathrm{gr}$, direndam formalin 0,4\% selama 6 jam dan $\mathrm{HCl} 1 \%$ selama 1 jam 1:30 (w/v). Ekstraksi dilakukan dengan $\mathrm{Na}_{2} \mathrm{CO}_{3} 2 \% 1: 30$ $(\mathrm{w} / \mathrm{v})$ dengan suhu $60-70^{\circ} \mathrm{C}$ selama 2 jam, kemudian disaring. Filtrat didekantasi selama 3 jam lalu ditambah $\mathrm{Ca} \mathrm{Cl}_{2} 0,5 \mathrm{M}$. Pemucatan dengan $\mathrm{NaOCl}$ teknis hingga berwarna putih kekuningan. Filtrat dikonversi menjadi asam alginat dengan direndam $\mathrm{HCl} 0,5 \mathrm{M}$ selama 12 jam dengan 3 tahap pergantian $\mathrm{HCl}$. Asam alginat dikonversi menjadi natrium alginat dengan ditambahkan bubuk $\mathrm{Na}_{2} \mathrm{CO}_{3}$ sebanyak $2,5 \mathrm{gr}$ dan direndam etanol teknis. Lembaran natirum alginat diblender menjadi tepung natrium alginat. Ekstraksi jalur kalsium MAE (Silva et al., 2015), mempunyai tahapan yang sama dengan ekstraksi jalur kalsium konvensional namun tidak menggunakan formalin dan menggunakan microwave sebagai alat ekstraksi. Masing-masing ekstraksi dengan 3 ulangan dan 3 konsentrasi $\mathrm{Ca} \mathrm{Cl}_{2}$ yang berbeda.

Rendemen hasil ekstraksi diuji kualitas alginatnya, uji kualitas meliputi persentase rendemen, kadar air, kadar abu, viskositas, pH dan FTIR. Data kualitas dianalisa statistik dengan Software SPSS 23. Hasil yang diperoleh di uji dengan metode two way Analysis of Variants (ANOVA) untuk mengetahui pengaruh konsentrasi $\mathrm{Ca}^{\mathrm{Cl}_{2}}$ yang berbeda terhadap kualitas alginat hasil metode ekstraksi jalur kalsium dan MAE.

\section{HASIL DAN PEMBAHASAN}

Hasil ekstraksi dari kedua metode berupa natrium alginat berwarna putih. Kualitas alginat dari ekstraksi Padina sp. (Tabel 1).

Rendemen natrium alginat berdasarkan konsentrasi $\mathrm{Ca} \mathrm{Cl}_{2}$ menunjukan nilai tertinggi pada metode ekstraksi MAE dengan konsentrasi $1,0 \mathrm{M}$ yaitu $26,83 \% \pm 0,02$. Berdasarkan uji two way ANOVA nilai $\mathrm{P}<0,05$ sehingga terdapat pengaruh signifikan konsentrasi $\mathrm{Ca} \mathrm{Cl}_{2}$. Faktor suhu menjadi penyebab tinggnya hasil rendemen alginat, pada suhu yang lebih tinggi, rendemen natrium alginat semakin tinggi, jika suhu meningkat maka frekuensi benturan antar molekul meningkat sehingga mudah ditembus oleh pelarut (Pasanda dan Aziz, 2016). Naiknya suhu menyebabkan degradasi yang terjadi di rantai makromolekul juga lebih besar (Fertah et al., 2017). 
Tinggi rendahnya rendemen $\mathrm{Na}$-alginat dapat dipengaruhi oleh jenis rumput laut, kondisi tempat tumbuh atau habitat, iklim dan metode ekstraksi yang digunakan (Rhein-Knudsen et al., 2017).

Kadar air natrium alginat yang dihasilkan dari semua metode sesuai dengan baku mutu kualitas alginat yaitu $<15 \%$. Kadar air tertinggi yaitu $11,67 \% \pm 0,15$ pada metode MAE dengan konsentrasi $\mathrm{Ca} \mathrm{Cl}_{2}$ sebesar 0,5 M. Pengujian statistik two way ANOVA menghasilkan nilai $\mathrm{P}>0,05$, sehigga tidak ada pengaruh signifikan antara penggunaan konsentrasi $\mathrm{Ca}^{\mathrm{Cl}_{2}}$ terhadap kadar air. Kadar air pada alginat dipengaruhi oleh proses perendaman alginat dengan larutan pada saat proses ekstraksi. Proses pengeringan alginat setelah diektraksi juga mempengaruhi kadar air didalam alginat, semakin lama proses penjemuran maka kadar air yang dihasilkan akan semakin sedikit (Latifi et al., 2015). Nilai kadar air yang seragam ini juga dikarenakan proses penjemuran alginat yang menggunakan jangka waktu yang sama pada setiap sampelnya yaitu \pm 12 jam penjemuran (Maharani et al., 2017).

Metode ekstraksi alginat menggunakan jalur kalsium menghasilkan kadar abu terendah $20,83 \% \pm 0,05$. Metode kalsium MAE menghasilkan kadar abu terendah sebesar $21,83 \% \pm 0,06$ pada konsentrasi $1,0 \mathrm{M} \mathrm{Ca} \mathrm{Cl}_{2}$. Faktor yang dapat menurunkan nilai kadar abu natrium alginat yaitu proses pencucian setelah pembentukan asam alginat hingga $\mathrm{pH}$ mendekati netral. Penambahan $\mathrm{HCl} 1 \%$ juga dapat menurunkan nilai kadar abu (Hetch dan Srebnik, 2016). Kadar abu pada penelitian ini menghasilkan nilai yang sesuai dengan baku mutu alginat yaitu pada nilai $18-27 \%$. Rumput laut Padina sp. merupakan salah satu spesies rumput laut yang ditempeli banyak kalsium sehingga mempertinggi mineral yang tedapat pada sampel rumput laut. Kadar abu yang terdapat pada hasil alginat bisa juga garam-garam yang melekat pada rumput laut.

Metode ekstraksi alginat menggunakan jalur kalsium menghasilkan viskositas terbesar yaitu sebesar 10,42 cPs $\pm 0,14$ pada konsentrasi $1,0 \mathrm{M} \mathrm{Ca} \mathrm{Cl}_{2}$. Metode ekstraksi yang ke-2 yaitu MAE menghasilkan viskositas tertinggi yaitu sebesar $11,42 \pm 0,14 \mathrm{cPs}$. Hasil uji two way ANOVA tidak menunjukan pengaruh yang signifikan dengan nilai $P>0,05$. Pengendapan dengan etanol, tidak efisien karena etanol mempunyai nilai polar yang sangat tinggi sehingga tidak efisien untuk mengikat gugus hidroksil $(-\mathrm{OH})$. Nilai polar yang semakin tinggi akan menyebabkan larutan semakin mendekti sifat air yang memiliki nilai sangat polar. Pelarut yang mempunyai nilai polar rendah dapat dengan mudah menarik molekul air dalam alginat dan menyebabkan alginat berbobot molekul tinggi sehingga meningkatkan viskositas alginat yang dihasilkan (Jian et al., 2014).

Metode ekstraksi alginat menggunakan jalur kalsium menghasilkan $\mathrm{pH}$ tertinggi sebesar $6,87 \pm 0,06$ pada konsentrasi $0,5 \mathrm{M} \mathrm{Ca} \mathrm{Cl}_{2}$. Metode ekstraksi MAE menghasilkan $\mathrm{pH}$ tertinggi sebesar $6,90 \pm 0,27$ pada konsentrasi $0,5 \mathrm{M} \mathrm{Ca} \mathrm{Cl}_{2}$. Uji statistik two way ANOVA menunjukan nilai $\mathrm{P}>0,05$ sehingga tidak ada pengaruh oleh konsentrsasi $\mathrm{Ca} \mathrm{Cl}_{2}$. Nilai $\mathrm{pH}$ yang dihasilkan dari ekstraksi rumput laut Padina sp. memenuhi kualitas baku mutu aginat. pH dari alginat dipengaruhi oleh berbagai macam faktor yaitu faktor internal dimana merupakan kandungan alami dari rumput laut itu sendiri yang disebabkan oleh lingkungan dan faktor eksternal yaitu berdasarkan proses ekstraksi. Natrium alginat akan stabil pada pH 5-10 sedangkan pada $\mathrm{pH}$ yang tinggi dapat menyebabkan viskositas yang dihasilkan akan sangat kecil (Bahar et al., 2012).

Tabel 1. Kualitas Natrium Alginat

\begin{tabular}{lcccccc}
\hline \multirow{2}{*}{ Parameter Uji } & \multicolumn{4}{c}{$\begin{array}{c}\text { Jalur Kalsium } \\
(\mu \pm \mathrm{SD}, \mathrm{n}=3)\end{array}$} & \multicolumn{2}{c}{$\begin{array}{c}\text { Jalur Kalsium (MAE) } \\
(\mu \pm \mathrm{SD}, \mathrm{n}=3)\end{array}$} \\
\cline { 2 - 7 } & $0,5 \mathrm{M}^{*}$ & $1,0 \mathrm{M}^{*}$ & $1,5 \mathrm{M}^{*}$ & $0,5 \mathrm{M}^{*}$ & $1,0 \mathrm{M}^{*}$ & $1,5 \mathrm{M}^{*}$ \\
\hline Rendemen (\%) & $14,89 \pm 00,5$ & $20,59 \pm 0,10$ & $18,59 \pm 0,04$ & $18,78 \pm 0,04$ & $26,83 \pm 0,02$ & $24,12 \pm 0,04$ \\
Kadar Air (\%) & $11,00 \pm 0,10$ & $9,00 \pm 0,10$ & $11,00 \pm 0,10$ & $11,67 \pm 0,15$ & $10,67 \pm 0,15$ & $11,33 \pm 0,17$ \\
Kadar Abu (\%) & $23,67 \pm 0,06$ & $20,83 \pm 0,05$ & $23,17 \pm 0,07$ & $26,83 \pm 0,03$ & $21,83 \pm 0,06$ & $24,00 \pm 0,05$ \\
Viskositas (cPs) & $8,23 \pm 0,25$ & $10,42 \pm 0,14$ & $9,17 \pm 0,19$ & $9,83 \pm 0,29$ & $11,42 \pm 0,14$ & $10,58 \pm 0,14$ \\
pH & $6,87 \pm 0,06$ & $6,57 \pm 0,11$ & $6,63 \pm 0,25$ & $6,90 \pm 0,27$ & $6,77 \pm 0,06$ & $6,63 \pm 0,29$ \\
\hline
\end{tabular}


Sampel alginat dari Pantai Pok Tunggal mempunyai bilangan gelombang yang sesuai dengan gugus fungsional alginat. Sampel hasil ekstraksi masing-masing memiliki gugus fungsional antara lain C-O strech (karboksil) pada bilangan gelombang 1300-1000 cm bilangan gelombang $1419-1411 \mathrm{~cm}^{-1}$. COO- asimetris pada bilangan gelombang $1620-1604 \mathrm{~cm}^{-1}$, $\mathrm{C}=\mathrm{O}$ strech (karbonil) pada bilangan gelombang 1700-1600 $\mathrm{cm}^{-1}$, O-H strech (hidroksil) pada bilangan gelombang $3500-3200 \mathrm{~cm}^{-1}$. Alginat yang dihasilkan mempunyai ciri khas dari alginat yang ditandakan dengan adanya sidik jari guluronat pada panjang gelombang $930-890 \mathrm{~cm}^{-1}$, sidik jari manuronat pada panjang gelombang $870-820 \mathrm{~cm}^{-1}$, dan natrium yang menandakan bahwa alginat yang dihasilkan merupakan natrium alginat pada panjang gelombang $1614-1431 \mathrm{~cm}^{-1}$.

Gugus-gugus fungsional yang terdapat pada alginat yang dihasilkan menunjukan bahwa yang diperoleh adalah Na-alginat. Gugus fungsi alginat adalah $\mathrm{COOH},-\mathrm{OH}, \mathrm{C}-\mathrm{O}-\mathrm{C}$ dan mempunyai kesamaan dengan dengan penelitian (Rhein-Knudsen et al., 2017; Pasanda dan Aziz, 2017; Diharningrum dan Husni, 2018 dan Pandit et al., 2019). Parameter lingkungan merupakan faktor yang mempengaruhi kualitas alginat. Hasil pengukuran parameter lingkungan pantai Pok Tunggal (Tabel 2).

Suhu di Pantai Pok Tunggal cenderung hangat yaitu pada nilai $30{ }^{\circ} \mathrm{C}$. Rumput laut dapat tumbuh pada suhu $\pm 20-30{ }^{\circ} \mathrm{C}$ (Kadi, 2015). Peningkatan suhu dapat menyebabkan penurunan kelarutan gas $\mathrm{O}_{2}, \mathrm{CO}_{2}, \mathrm{~N}_{2}$ dan $\mathrm{CH}_{4}$ dalam air (Prasetyaningsih dan Rahardjo, 2016) sehingga dapat mengurangi jumlah kandungan DO (dissolved oxygen) di perairan (Widyartini et al., 2017). Salinitas di Pantai Pok Tunggal mempunyai nilai 30 \%. Salinitas optimal untuk pertumbuhan rumput laut berkisar 31-32 ppt (Herlinawati et al., 2018). Kandungan oksigen terlarut atau Dissolved Oxygen di perairan Pantai Pok Tunggal cukup tinggi yaitu $6,72 \mathrm{mg} / \mathrm{L}$. Tingkat DO (dissolved oxygen) optimal untuk pertumbuhan rumput laut adalah sekitar $>4,54 \mathrm{mg} / \mathrm{L}$ (Kasim et al., 2017). Perairan Pantai Pok Tunggal mempunyai nilai $\mathrm{pH}$ yaitu 8,5. Rumput laut dapat bertahan pada $\mathrm{pH}$ 7-8,5 (Kadi, 2015).

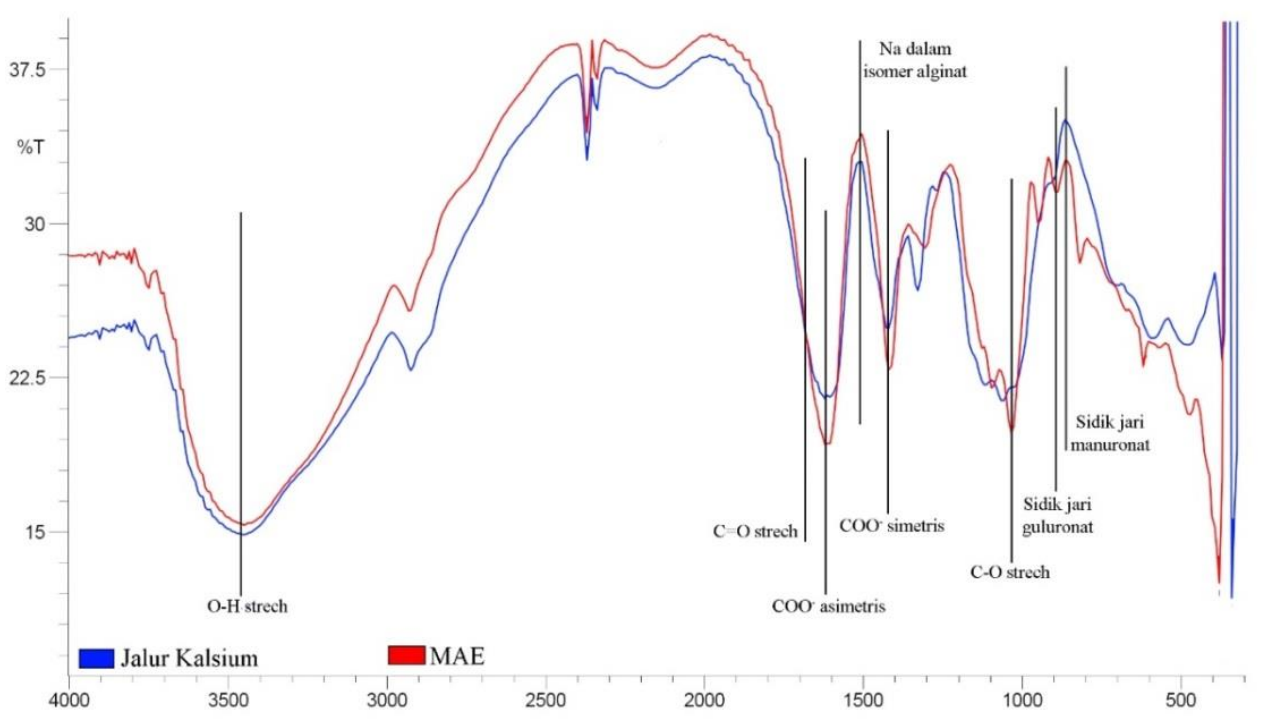

Gambar 1. Hasil FTIR alginat

Tabel 2. Hasil Pengukuran parameter lingkungan perairan Pantai Pok Tunggal (KLH, 2004)

\begin{tabular}{lcc}
\hline \multicolumn{1}{c}{ Parameter Lingkungan } & Pantai Pok Tunggal, Gunung & Kidul \\
\hline Suhu $\left({ }^{\circ} \mathrm{C}\right)$ & 32 & $21-30$ \\
Salinitas $(\% \circ)$ & 30 & $28-34$ \\
DO (Dissolved oxygen) $(\mathrm{mg} / \mathrm{L})$ & 6,72 & $>5$ \\
pH & 8,5 & $7-8,5$ \\
Substrat & Karang Berpasir & - \\
\hline
\end{tabular}




\section{KESIMPULAN}

Berdasarkan hasil penelitian dapat disimpulkan bahwa kualitas $\mathrm{Na-alginat} \mathrm{Padina} s p$. dari pantai Pok Tunggal, Kabupaten Gunung Kidul sudah memenuhi standar baku mutu. Penggunaan metode ekstraksi sangat berpengaruh terhadap kualitas alginat yang dihasilkan. Metode MAE menghasilkan rendemen alginat yang lebih tinggi dibandingkan metode ekstraksi jalur kalsium konvensional. Konsentrasi $\mathrm{Ca} \mathrm{Cl}_{2}$ berpengaruh terhadap kualitas alginat, mutu dari alginat yang paling baik dihasilkan oleh ekstraksi dengan $\mathrm{Ca} \mathrm{Cl}_{2}$ sebesar 1,0 M.

\section{UCAPAN TERIMAKASIH}

Artikel ini adalah bagian dari Skripsi yang berjudul "Perbandingan Kualitas Natrium Alginat dari Rumput Laut (Padina sp.) dengan Menggunakan Metode Ekstraksi yang Berbeda" sebagai syarat memperoleh gelar Sarjana Strata Satu Program Studi IImu Kelautan Fakultas Perikanan dan Ilmu Kelautan, Universitas Diponegoro.

\section{DAFTAR PUSTAKA}

Abid, M.D., Lajili, S., Ammar, H.H., Cherif, D., Eltaief, N., Majdoub, H. \& Bouraoui, A. 2019. Chemical and Biological Properties of Sodium Alginates Isolated from Tow Brown Algae Dictyopteris Membranaceae and Padina Pavonica. Trends Journal of Sciences Research, 4(2):62-67.

Anwar, F., Djunaedi, A. \& Santosa, G.W. 2013. Pengaruh Konsentrasi KOH yang Berbeda Terhadap Kualitas Alginat Rumput Laut Coklat Sargassum duplicatum J. G. Agardh. Journal of Marine Research, 2(1):7-14.

Asih, T., Khayuridlo, M., Noor, R. \& Muhfahroyin. 2019. Biodiversity and Potential Use of Macro Algae in Pesisir Barat Lampung. Biosaintifika, 11(1):100-107.

Bahar, R., Arief, A. \& Sukriadi. 2012. Daya Hambat Ekstrak Na-alginat dari Alga Coklat Jenis Sargassum sp. Terhadap Proses Pematangan Buah Mangga dan Buah Jeruk. Jurnal Indonesia Chimica Acta, 2(5):22-31.

Diharningrum, I.M. \& Husni, A. 2018. Metode Ekstraksi Jalur Asam dan Kalsium Alginat Berpengaruh pada Mutu Alginat Rumput Laut Cokelat Sargassum hystrix J. Agardh. Jurnal Pengolahan Hasil Perikanan Indonesia, 21(3):532-542.

Fertah, M., Belfkira, A., Dahmane, E.M., Taourirte, M. \& Brouillette, F. 2017. Extraction and Characterization of Sodium Alginate from Moroccan Laminaria digitata Brown Seaweed. Arabian Journal of Chemistry, 10(3):3707-3714.

Herlinawati, N.D.P.D., Arthana I.W. \& Dewi, A.P.W.K. 2018. Keanekaragaman dan Kerapatan Rumput Laut Alami Perairan Pulau Serangan Denpasar Bali. Journal of Marine and Aquatic Sciences, 4(1):22-30.

Hetch, H. \& Srebnik, S. 2016. Structural Characterization of Sodium Alginate and Calcium Alginate. Biomacromolecules, 17:2160-2167.

Husni, A., Subaryono, Pranoto, Y., Tazwir \& Ustadi. 2012. Pengembangan Metode Ekstraksi Alginat dari Rumput Laut Sargassum sp. Sebagai Bahan Pengental. Agritech, 32(1):1-8.

Jian, H., Lin, X., Zhang, W., Zhang, W. M., Sun, D. \& Jiang, J. 2014. Characterization of Fractional Precipitation Behaviour of Galactomannan Gums with Ethanol and Isopropanol. Food Hydrocolloids, 40:115-121.

Kadi, A. 2015. Karakteristik Makro Algae Berzat Kapur di Perairan Tanjung Sira Lombok-Barat. Biosfera, 32(1):51-58.

Kasim, S., Marzuki, A. \& Sudir, S. 2017. Effects of Sodium Carbonate Concentration and Temperature on the Yield and Quality Characteristics of Alginate Extracted from Sargassum sp. Research Journal of Pharmaceutical, Biological, and Chemical Sciences, 8(1):660-668.

Kementerian Lingkungan Hidup [KLH]. 2004. Keputusan Menteri Negara Lingkungan Hidup Nomor 51. 
Latifi, A.M., Nejad, E.S. \& Babavalian, H. 2015. Comparison of Extraction Different Methods of Sodium Alginate from Brown Alga Sargassum sp. Localized in the Southern of Iran. Journal of Applied Biotechnology Reports, 2(2):251-255.

Maharani, A.A., Husni, A. \& Ekantari, N. 2017. Karakteristik Natrium Alginat Rumput Laut Cokelat Sargassum fluitans dengan Metode Ekstraksi yang Berbeda. Jurnal Pengolahan Hasil Perikanan Indonesia, 20(3):478-487.

Mirza, M., Ridlo, A. \& Pramesti, R. 2013. Pengaruh Perendaman Larutan $\mathrm{KOH}$ dan $\mathrm{NaOH}$ Terhadap Kualitas Alginat Rumput Laut Sargassum polycycstum C.A. Agardh. Journal of Marine Research, 2(1):41-47.

Mushollaeni, W. \& Rusdiana, E. 2011. Karakterisasi Natrium Alginat dari Sargassum sp., Turbinaria sp. dan Padina sp. Jurnal Teknologi dan Industri Pangan, 1(22):26-32.

Pandit, P., Gayatri T.N. \& Regubalan, B. 2019. Alginates Production, Characterization and Modification. Alginates: Applications in the Biomedical and Food Industries, 2 : 21-44.

Pasanda, O.S.R. \& Aziz, A. 2018. The Extraction of Brown Algae (Sargassum sp.) Through Calcium Path to Produce Sodium Alginate. Jurnal Bahan Alam Terbarukan, 7(1):109-112.

Prasetyaningsih, A. \& Rahardjo, D. 2016. Keanekaragaman dan Bioaktivitas Senyawa aktif Makroalga Pantai Wediombo Kabupaten Gunung Kidul. Jurnal Agrisains, 17(1):107-115.

Prasetyo, S.S., Juliani, O. \& Sugih, A.K. 2017. Isolasi Alginat Rumput Laut Coklat (Sargassum sp.) menggunakan Jalur Kalsium Alginat. Prosiding Seminar Nasional Teknik Kimia "Kejuangan". Pengembangan Teknologi Kimia untuk Pengolahan Sumber Daya Alam Indonesia. Yogyakarta.

Rhein-Knudsen, N.R., Ale, M.T., Ajalloueian, F. \& Meyer, A.S. 2017. Characterization of Alginates from Ghanaian Brown Seaweeds : Sargassum spp. and Padina spp. Food Hydrocolloids, 71:236-244.

Septiani, E., Pratama, G. \& Putri, R.M.S. 2017. Kandungan Na-Alginat dari Rumput Laut Padina sp. Menggunakan Konsentrasi Kalium Hidroksida yang Berbeda. Biosfera, 34(3):110 -116.

Silva, M., Gomes, F., Oliveira, F., Morais, S. \& Delerue-Matos, C. 2015. Microwave-Assisted Alginate Extraction from Portuguese Saccorhiza polyschides-Influence of Acid Pretreatment. International Journal of Biotechnology and Bioengineering, 9(1):30-33.

Sinurat, E. \& Marliani, R. 2017. Karakteristik Na-Alginat dari Rumput Laut Cokelat Sargassum crassifolium dengan Perbedaan Alat Penyaring. Jurnal Pengolahan Hasil Perikanan Indonesia, 20(2):351-361.

Widiyanti, P. \& Siswanto. 2012. Physical characteristic of Brown Algae (Phaeophyta) from Madura Strait as Irreversible Hydrocolloid Impression Material. Dental Journal, 45(3):177-180.

Widyartini, D.S., Widodo, P. \& Susanto, A.B. 2017. Thallus variation of Sargassum polycystum from Central Java, Indonesia. Biodeversitas, 18(3):1004-1011. 